\title{
Defined Observation Focal Duration
}

National Cancer Institute

\section{Source}

National Cancer Institute. Defined Observation Focal Duration. NCI Thesaurus. Code C93777.

A quantity of time in which the observation result is held to be true. 